\title{
IMPACT OF LARGE SCALE DAM CONSTRUCTION ON MOVEMENT CORRIDORS OF MAMMALS IN ARTVIN, NORTH- EASTERN TURKEY
}

\author{
KAYA ÖZDEMIREL, B. ${ }^{{ }^{*}}-$ TURAK, A. S. ${ }^{2}-$ BILGIN, C. C. ${ }^{1}$ \\ ${ }^{1}$ Biodiversity and Conservation Laboratory, Department of Biology, Middle East Technical \\ University (METU), 06800 Ankara, Turkey \\ ${ }^{2}$ Nature Conservation Center, 06460 Ankara, Turkey \\ *Corresponding author \\ e-mail: banukaya00@gmail.com \\ (Received $3^{\text {rd }}$ Dec 2015; accepted $25^{\text {th }}$ Apr 2016)
}

\begin{abstract}
The long term viability of many animals depends on maintaining connection between their subpopulations. However, man-made infrastructures can severely damage the connection of subpopulations through fragmenting prime habitats. Our goal in this study is to investigate impact of a series of dam constructions on the potential movement corridors of the wild goat (Capra aegragus), Eurasian lynx (Lynx lynx), and the golden jackal (Canis aureus) in northeastern Turkey. We used one of the most common approaches, least cost corridor modeling to determine movement corridors of target species for before and after dam constructions and compared the differences in physical structures, habitat suitability and total cost of movement in corridors. We found that constructions of dams would negatively affect subpopulations of target species and their movement corridors. Some subpopulations are expected to lose suitable habitat to flooding while others to be divided into distant, smaller units once the construction is completed. Moreover, resistance to movement will increase due to a decline in habitat suitability and an increase in total cost of movement. In brief, dams and their reservoirs in northeastern Turkey will likely become serious barriers and considerably constrain movements of target species within and between subpopulations.
\end{abstract}

Keywords: animal movement, corridors, dam construction, fragmentation, least cost corridor modeling, Turkey

\section{Introduction}

Habitat loss and fragmentation are among major threats facing biodiversity (Rosenberg et al., 1997; Myers et al., 2000; Macdonald, 2003; Jongman, 2004). Such processes usually lead to isolated populations that have a higher risk of extinction due to higher demographic stochasticity and increased rates of inbreeding (Mills and Smouse, 1994; Riley et al., 2006; Sawyer et al., 2011). Impacts of fragmentation on isolated populations can be mitigated by providing connectivity with corridors (Beier et al., 2006; Crooks and Sanjayan, 2006; Sawyer et al., 2011). Corridors are "natural vegetation strips running between the reserves" (Bentley and Catteral, 1997; Beier and Noss, 1998). They increase colonization (Hale et al., 2001), promote movement and dispersal (Briers, 2002; Beier et al., 2008; LaPoint et al., 2013) and facilitate gene flow (Beier, 2011; LaPoint et al., 2013; Saura et al., 2014).

Although, functions of corridors are well defined within the metapopulation concept of conservation biology, there are some doubts about their efficiency due to limited empirical research (Shkedy and Saltz, 2000; Niemela, 2001; Fagan and Calabrese, 2006; Parks et al., 2013). Early studies about efficiency of corridors were mostly based on comparison of individual densities between connected and unconnected habitat 
patches (Mac Clintock et al., 1977; Merriam and Lanove, 1990; Machtons et al., 1996; Haddad and Baum, 1999). However, later studies do not only rely on observations, but also demonstrate gene flow occurring between isolated populations through corridors (Manel et al., 2003; Proctor et al., 2004; Dixon et al., 2006; Riley et al., 2006). In this context, corridors have become a fundamental component to supply long term viability for populations (Beier, 1993; Fahrig and Merriam, 1994; Noss et al., 1996; MateoSanchez et al., 2014). Therefore, designing and retaining corridors has had high priority in biodiversity conservation in recent years (Kusak et al., 2009).

Conservation organizations and agencies also focus on the significance of corridors for wildlife conservation and corridors are becoming an integral parts of conservation plans (Anderson and Jenkins, 2006; Morrison and Boyce, 2009). Such corridors may be especially critical for large mammals which are highly susceptible to the habitat fragmentation (Dixon et al., 2006). Large mammals are wide ranging animals and they require large home ranges and accomplish long distance dispersals. Hence, they are more likely to use corridors for movement (Harrison and Voller, 1998). However in some cases, human induced developments can irreversibly damage existing movement corridors of animals.

We present here the possible effects of a large scale hydroelectric power project along River Çoruh in northeastern Turkey on wildlife connectivity (Fig. 1). A series of dams are either planned, under construction or have been completed along this fast flowing river. These dam constructions may create barriers for wildlife by severing habitat connectivity between a numbers of sites. In this study, our aim is to investigate the possible impacts of this series of constructions on potential movement corridors of the wild or bezoar goat (Capra aegragus), Eurasian lynx (Lynx lynx), and the golden jackal (Canis aureus). We modeled potential movement corridors of these target species as before and after dam construction using least cost modeling. Subsequently, differences in movement corridors for before and after constructions were investigated and finally, a general conclusion was drawn to emphasize major consequences of the impact of dam constructions and some suggestions were made to mitigate these impacts.

\section{Material and methods}

\section{Study area}

Our study area is in northeastern Turkey and lies in between latitude 41.15 to 42.60 and longitude 40.40 to 41.55 (Fig. 1 a). The area is about $10,000 \mathrm{~km}^{2}$ and encompasses parts of Artvin and northern districts of Erzurum including the River Çoruh valley. The study area has several remarkable geographic features. It is characterized by high mountains, broad plateaus and deep valleys, and has a vast altitude range of roughly between 65 to $3500 \mathrm{~m}$ (Fig. 1 b). River Çoruh is approximately $431 \mathrm{~km}$ long, of which $410 \mathrm{~km}$ lies within Turkey. It flows in a deep valley, flanked by some of the tallest mountains in the country (e.g. Vercenik Peak of $3711 \mathrm{~m}$ ) and empties into the Black Sea around Batumi, Georgia (Fig. 1). This varied topography is covered by humid temperate forest in the north and dry high mountain steppe-meadows in the south (Bilgin et al., 2006; unpublished data). Most common stand forming species are Scots pine (Pinus sylvestris), oriental spruce (Picea orientalis), Black Sea fir (Abies nordmannia), oriental beech (Fagus orientalis), alders (Alnus spp.) and oaks (Quercus spp.) Moreover, Çoruh valley that bisects the area roughly in the middle is dominated by a relict Mediterranean type vegetation including maquis elements such as Arbutus andrachne, Laurus nobilis, 
Rhus coriaria, Ruscus aculeatus and stone pine (Pinus pinea) (Eminağaoğlu and Anşin, 2003). These heterogeneous communities provide habitat for many native wildlife species such as brown bear, wild goat, Alpine chamois, Eurasian lynx, grey wolf, golden jackal, red fox, stone marten and possibly even leopard (Ambarlı and Bilgin, 2008; Gundogdu and Ogurlu, 2009; Ambarlı et al., 2010; Gokturk et al., 2011; Ambarl1 and Bilgin, 2012; Sekercioglu, 2012).

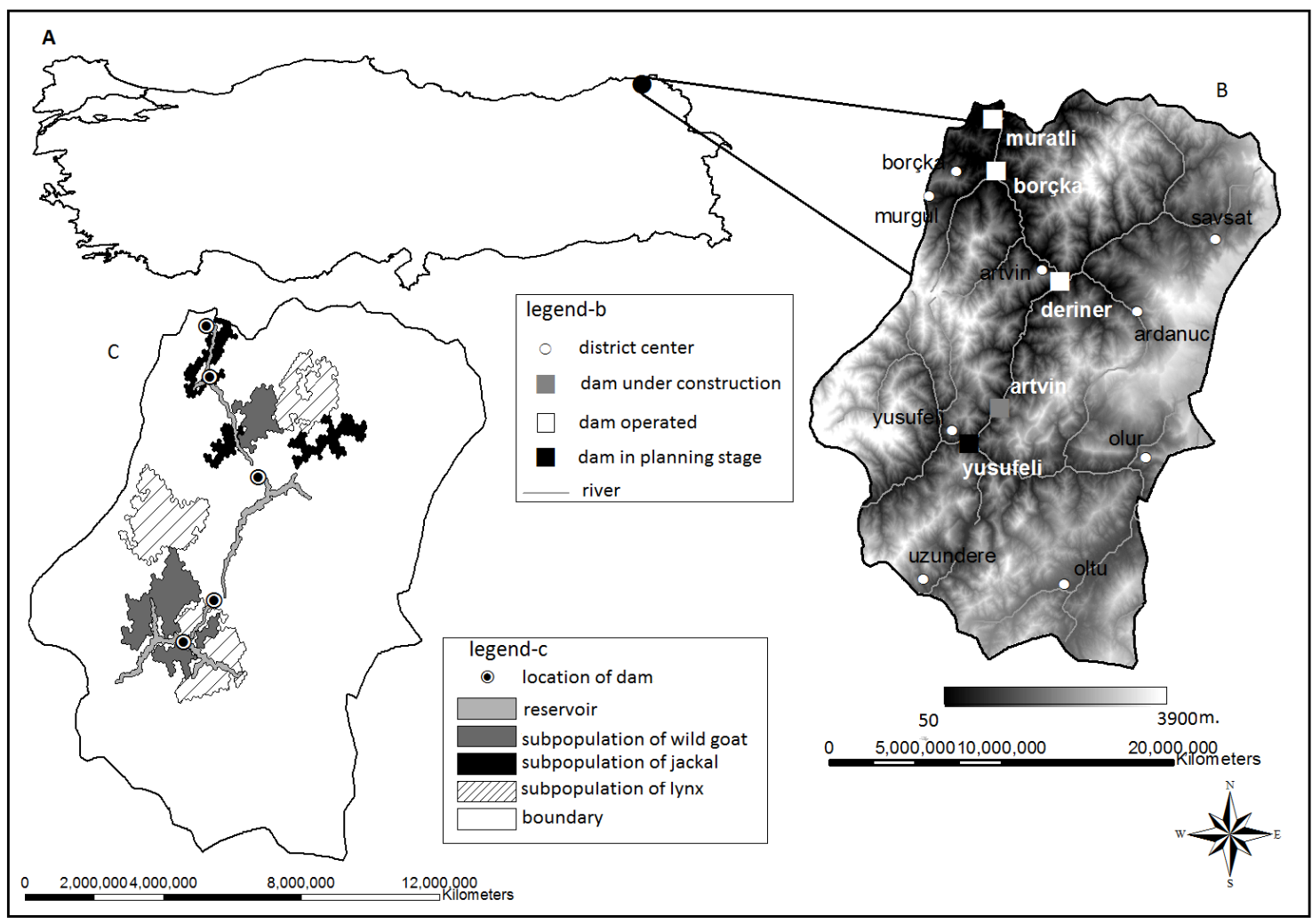

Figure 1. a. Geographic location of the study area; $b$. location and condition of dams with digital elevation model of the area; c dam reservoirs and local subpopulations of target species

\section{Modelled species}

For modeling, we selected a diurnal ungulate, a social canid and a solitary felid since they represent different functional groups and/or their occurrences only partially overlap within the elevational gradient of the area. This allows us to evaluate the effects of dams for a broad altitude range and a wider range of ecological requirements, although it may not always be possible to extend findings to other species due to differences in spatial ecology or behavior.

Wild goat is a medium-sized, sexually-dimorphic ungulate that occurs throughout western Asia. It inhabits mountainous areas, where there is a mixture of rocky outcrops and shrubby vegetation or dry conifer woodland (Shackelton, 1997). For most of the year sexes remain separate, with females and their young forming stable groups, except during the mating season in late fall, when males can travel long distances to join receptive females (Turan, 1984; Gundogdu, 2011). In the study area, they range from about $500 \mathrm{~m}$. to $2500 \mathrm{~m}$. (Bilgin et al., 2006). Most ungulates require good visibility on a horizontal plane and a moderate amount of cover for crossing unknown territory 
(Kintsch and Cramer, 2011). Cliff-dwelling species, such as ibex, have been observed to use steep terrain while travelling between core zones since they rely on their ability to move fast in such terrain in face of danger (e.g. Shkedy and Saltz, 2000). While passing through overpasses or underpasses, they prefer a natural substrate and clear lines of sight from one end to the other (Kintsch and Cramer, 2011). This suggests wild goats stay away from paved surfaces, especially when there is no escape terrain in close proximity. They probably also avoid constrained spaces such as narrow foot bridges.

Golden Jackal (hereafter "jackal") is a medium-sized canid that occurs in south and west Asia, eastern Africa and southeastern Europe. It is an adaptable, opportunistic and social species that feeds on small mammals, birds or carrion. Jackals can trot long distances in search of food and will venture into human dominated landscapes (Turan, 1984; Jhala and Moehlman, 2004). In the study area, they occur from sea level up to $1200 \mathrm{~m}$. altitude, probably constrained by the presence of wolves at the upper limit of their range (Bilgin et al., 2006; Ambarlı and Bilgin, 2012). Most canids make use of paved roads, including man-made bridges, especially under cover of darkness (Kintsch and Cramer, 2011). For example, coyotes are known to use a variety of structure types, including culverts, underpasses and bridges (Way, 2009). Similarly, Blanco et al. (2005) showed that Spanish wolves regularly used vehicle bridges to cross a highway and a river. Jackals are assumed to behave similarly; in fact, they are commonly found as road casualties on roads and bridges in Turkey (unpublished data). This is supported by the fact that road mortality made up almost half of all recorded deaths in Italy during 19842011 (Lapini et al., 2011), and that they are the most common road killed species in India besides dogs (Jhala and Moehlman, 2004).

Eurasian lynx (hereafter "lynx") is a medium-sized felid with a solitary existence, except when females are accompanied by dependent young. It is distributed in suitable habitats over most of northern Eurasia, typically preying on small ungulates or lagomorphs (Nowell and Jackson, 1996). Subadult males can move up to $150 \mathrm{~km}$. during natal dispersal (Schmidt, 1998; Samelius et al., 2011). In our study area, the species is associated with open woodland or scrubland between $800 \mathrm{~m}$. and $2000 \mathrm{~m}$. (Bilgin et al., 2006; Ambarlı et al., 2010). On the other hand, lynx require some sort of cover to cross unfamiliar territory. However, it can easily climb trees and do not hesitate to use logs across streams as bridges.

\section{Habitat suitability models}

The habitat suitability models for jackal, lynx and wild goat were originally produced within the scope of another project covering the Turkish Lesser Caucasus (Bilgin et al., 2006). Prior to the corridor analysis, we revised and refined these models by using information obtained from new species records. The suitability models were built using digital layers of elevation, slope, land cover, human population density and settlement patterns. The land cover surface of 20 (twenty) classes, was produced by the classification of Landsat TM images with the aid of terrain layers and digitized forest stand maps. 90-m pixel resolution Shuttle Radar Topographic Mission (SRTM) digital elevation model was used for slope and elevation. The human population density layer was based on the census data and distance to settlements was calculated in order to define settlement patterns.

Using presence records, we identified attributes of the variables affecting the distribution of target species. This information, together with that provided by wildlife experts, was then used in building a fuzzy relationship function describing the 
association for each environmental variable with habitat suitability for the target species (Table 1). Fuzzy suitability layers were then produced, by applying these fuzzy distribution functions. The suitability values in these layers range from 0.00 (least suitable) to 1.00 (most suitable). Wildlife experts then ranked the fuzzy suitability layers according to their importance for the target species, in order to assign a weight for each layer. Ranking is a popular decision support aid (Store and Kangas, 2001; Clevenger et al., 2002), and provides a flexible way for determining relative weights of the variables in habitat models (Kovacs et al., 2004). Our ranking relied on personal experience, ecological requirements of target species (LaRue and Nielsen, 2008) and correlation of modeling variables. Additionally, we generated a constraint layer for each of the target species. We then calculated the weighted linear combination of fuzzy layers and this constraint layer, using the modeling equation:

$$
H S M=\sum \mathrm{Wi}(f f s i) *(c l)
$$

where $H S M$ is the habitat suitability model, $\mathrm{W}_{\mathrm{i}}$ is weight of i'th variable (fuzzy suitability layer), $\mathrm{ffs}_{\mathrm{i}}$ is the $\mathrm{i}^{\prime}$ th fuzzy suitability layer and $c l$ is constraint layer. Values in the resulting layers ranged between 0.00 and 1.00, and indicated the probability of occurrence of each species, limited by the impact of constraints. These habitat suitability layers were used as a basis for the least cost corridor modeling procedure.

Table 1. Fuzzy suitability functions and weights for environmental variables used to produce of habitat suitability models of target species

\begin{tabular}{|c|c|c|}
\hline Variable & Fuzzy Functions & Weight \\
\hline \multicolumn{3}{|l|}{ Golden Jackal } \\
\hline Elevation (dem) & $\begin{array}{l}\text { dem }=0 \mathrm{~m}, \quad 1 ; \quad \operatorname{dem}>1500 \mathrm{~m}, \quad 0 ; \quad 0 \mathrm{~m}<\mathrm{dem}<1500 \mathrm{~m}, \\
\text { decreasing sigmoid distribution range between } 0 \text { and } 1\end{array}$ & 0.20 \\
\hline Slope (slp) & $\begin{array}{l}0^{\circ} \leq \operatorname{slp}<35^{\circ}, 1 ; \operatorname{slp}=45,0.5 ; \operatorname{slp} \geq 35^{\circ} \text { decreasing } \mathrm{J} \text { - shaped } \\
\text { distribution range between } 0 \text { and } 1\end{array}$ & 0.10 \\
\hline Land Cover (ld.c) & $\begin{array}{l}\text { snow, water, } 0 \text {; mixed humid coniferous broad leafed } \\
\text { forests (10 classes), } 0.7 \text {; damaged oak forest, semi- } \\
\text { drought oak forest, } 1 \text {; agriculture, meadow-alpine } \\
\text { meadow, open areas, sparse vegetation, decreasing } \\
\text { sigmoid distribution, } 2 \mathrm{~km} \text { away from vegetation }=0 \text {, }\end{array}$ & 0.30 \\
\hline $\begin{array}{l}\text { Distance to Settlements } \\
\text { (dis.stt) }\end{array}$ & $\begin{array}{l}\text { dis.stt }<250 \mathrm{~m}, 0 ; \text { dis.stt }=1500 \mathrm{~m}, 1 ; \text { dis.stt } \geq 250 \text {, } \\
\text { increasing sigmoid distribution range between } 0 \text { and } 1\end{array}$ & 0.20 \\
\hline Population Density (pop) & $\begin{array}{l}\text { pop }>1000, \quad 0 ; \quad \text { pop }=0, \quad 1 ; \quad 0 \leq p o p \leq 1000, \text { decreasing } \\
\text { sigmoid distribution range between } 0 \text { and } 1\end{array}$ & 0.20 \\
\hline \multicolumn{3}{|l|}{$\underline{\text { Wild Goat }}$} \\
\hline Elevation (dem) & $\begin{array}{l}\text { dem }<500 \mathrm{~m} \text { and } \operatorname{dem}>3000 \mathrm{~m}, 0 ; 1000 \mathrm{~m}<\mathrm{dem}<2000 \mathrm{~m} \text {, } \\
1 ; \\
500 \mathrm{~m} \leq \mathrm{dem} \leq 3000 \mathrm{~m} \text {, left skewed normal distribution } \\
\text { range between } 0 \text { and } 1\end{array}$ & 0.15 \\
\hline
\end{tabular}


Slope (slp)

Land Cover (ld.c)

Distance to Settlements

(dis.stt)

Population Density (pop)

$\underline{\text { Lynx }}$

Elevation (dem)

Slope (slp)

Land Cover (ld.c)

Distance to Settlements

(dis.stt)

Population Density (pop) $\operatorname{slp}<20^{\circ}, 0 ; \operatorname{slp}=35^{\circ}, 1 ; 20^{\circ} \leq \operatorname{slp} \leq 35^{\circ}$, sigmoid distribution

range between 0 and 1

snow, water, agriculture, mixed humid coniferous broad

leafed forests (10 classes), 0; meadow-alpine meadow, open areas, sparse vegetation, 1; damaged oak forest, semi-drought oak forest, oak-juniper forest, 0.5

dis.stt $<1500 \mathrm{~m}, 0$; dis.stt $=500 \mathrm{~m}, 1 ; 1500 \leq$ dis. $\mathrm{stt} \leq 5000$,

increasing sigmoid distribution range between 0 and 1

pop $>600,0 ;$ pop $=0,1 ; 0 \leq p o p \leq 600$, decreasing sigmoid

distribution range between 0 and 1

$\operatorname{dem}>2500, \quad 0 ; \quad 1000<\operatorname{dem}<2000, \quad 1 ; \quad 0 \leq \operatorname{dem} \leq 2500$,

normal distribution range between 0 and 1

$25^{\circ} \leq \operatorname{slp} \leq 35^{\circ}, 1 ; \operatorname{slp}=45^{\circ}$ and $\operatorname{slp}=10^{\circ}, 0.5 ; 0^{\circ} \leq \operatorname{slp} \leq 90^{\circ}$,

symmetric J-distribution range between 0 and 1

snow, water, agriculture, open areas, sparse vegetation,

meadow-alpine meadow, 0 ; , mixed humid coniferous broad leafed forests (13 classes), 1

dis.stt $<1000 \mathrm{~m}, \quad 0$; dis.stt $=3500 \mathrm{~m}, \quad 1$; dis.stt $\geq 1000$, increasing sigmoid distribution range between 0 and 1

Pop $=0,1 ; \quad$ pop $=100,0 ; \quad$ pop $\geq, 0$ decreasing sigmoid

\section{Local subpopulations}

We determined local subpopulation cores for jackal, wild goat and lynx using their respective suitability models, and corroborated the resulting maps with additional presence data. Areas with high habitat suitability values, especially clusters of such suitable areas indicate sites with high densities of target species (WHCWG, 2010; Beier et al., 2011). Based on our knowledge of each species' occurrence in the study area, we defined a suitability value of $0.90,0.80$ and 0.95 as thresholds for jackal, wild goat and lynx, respectively and assigned planning units with an average suitability value higher than these thresholds as core areas for subpopulations. These thresholds resulted in the designation of three local subpopulations for jackal and wild goat each, and four for lynx (Fig. 1c). These core areas coincide with the approximate locations of actual local subpopulation cores.

Of the study species, both wild goat and jackal are largely restricted to the large valley formed by River Coruh, although the range of the former extends to southwest and of the latter to northwest. The lynx occurs more widely. Natural movements of all three species in and out of the study area are restricted by very high mountains and/or unfavorable habitats that surround it. 


\section{Protected areas}

In the study area, there are nine legal protected areas of which four are national parks, two are wildlife reserves, two are strict nature reserves and one is a nature park (Fig. 2). Their corresponding layer was included in corridor modeling since protected areas are far from human pressures and more sheltered than unprotected landscape. They act as refuges and provide survival for target species. Moreover, they enable connectivity between habitat patches behaving like stepping stone corridors. Thus, they facilitate animal dispersal and movements. With these functions, protected areas increase habitat suitability for target species and provide priority sites for corridor design.

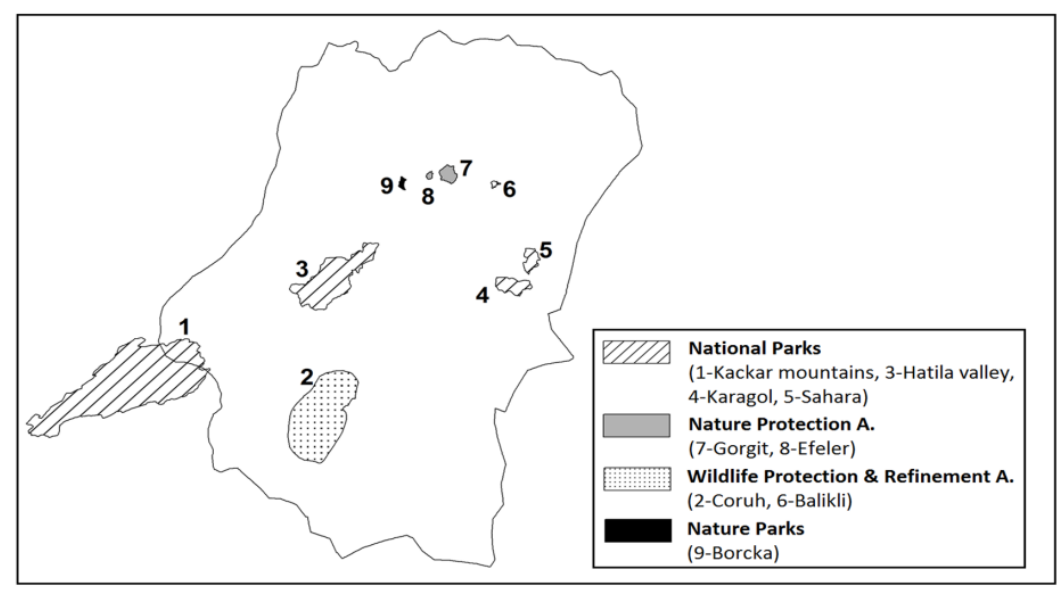

Figure 2. The map showing distribution and status of legally established protected areas

We expressed functions related to protected areas using protection coefficients. These coefficients were based on the actual status of protection at those sites. Accordingly, national parks with better protection were assigned 1 for protection coefficient, while a value of 0.66 was assigned for other protected areas. The resulting layer reflected level of protection and functions of protected areas as refuges and dispersal corridors for target species.

\section{Dams and reservoirs}

A series of five dams have been planned on River Çoruh (Fig. 1c), with constructions starting from the lower reaches and proceeding upstream (Sucu and Dinç, 2008). The first one, Muratli Dam, lies to the north of our study area. Its construction was completed and is operational since 2005 (Fig. 1b). Another two, Borçka and Deriner Dams are respectively located around centre of Borçka and $5 \mathrm{~km}$ south of the town of Artvin. They were both completed and began to hold water in 2012 (Fig. 1b). A fourth dam planned to be built is the Artvin Dam, which is still in the planning stage, and there is no construction activity yet (Fig. 1b). Finally, the Yusufeli Dam is under construction since 2013 and is planned to be operational by 2018 (Fig. 1b). Although, not all of these dams had begun to hold water, we produced a dam layer assuming their reservoirs filled with water. A digital elevation model was used as the primary input to generate this dam layer and the extent of reservoirs was determined by reclassifying elevation model along the river according to the maximum water level for each dam. The dam layer was included in corridor modeling analysis only for the situation after dam construction and used as an absolute barrier for target species. 


\section{Least cost corridor modeling}

Movement corridors were designed using least cost modeling before and after dam construction between each local subpopulation of a target species. Least cost modeling is the most widely used approach to design movement corridors or movement paths for wildlife species (LaRue and Nielsen, 2008; Sawyer et al., 2011). This approach delineates the most likely used routes by calculating the lowest cumulative cost of movement between two patches of suitable habitat (Verbeylen et al., 2003; Larkin et al., 2004; Chetkiewicz and Boyce, 2009). Unlike least cost paths, least cost corridors do not limit the width to a single pixel resolution (Verbeylen et al., 2003; Beier et al., 2009); instead, they include the most permeable slice of the area (Sawyer et al., 2011). In other words, they encompass the most suitable habitat to move with least resistance and fewest barriers (Larkin et al., 2004; Larue and Nielsen, 2008; Poor et al., 2012; Zeller et al., 2012). Therefore, least cost corridor modeling is an appropriate approach to determine the best theoretical wildlife corridors for target species both before and after dam constructions.

Analyses were performed using corridor planning tool of Idrisi Andes. The tool applies cost distance procedure and builds least cost corridors on measures of suitability for movement. It firstly constitutes a movement suitability surface. The surface consists of an aggregation of all factors effecting resistance to/ease of movement, such as habitat suitability, presence of barriers or other resistance structures, or protection. This surface is used to calculate the cost of travel from one point to another and a least cost path is delineated. This is the route with least resistance. Afterwards, a cost distance is calculated from the least cost path and the mean relationship between cost distance and spatial distance is determined to assign a cost threshold for designing movement corridors (Fig. 3).
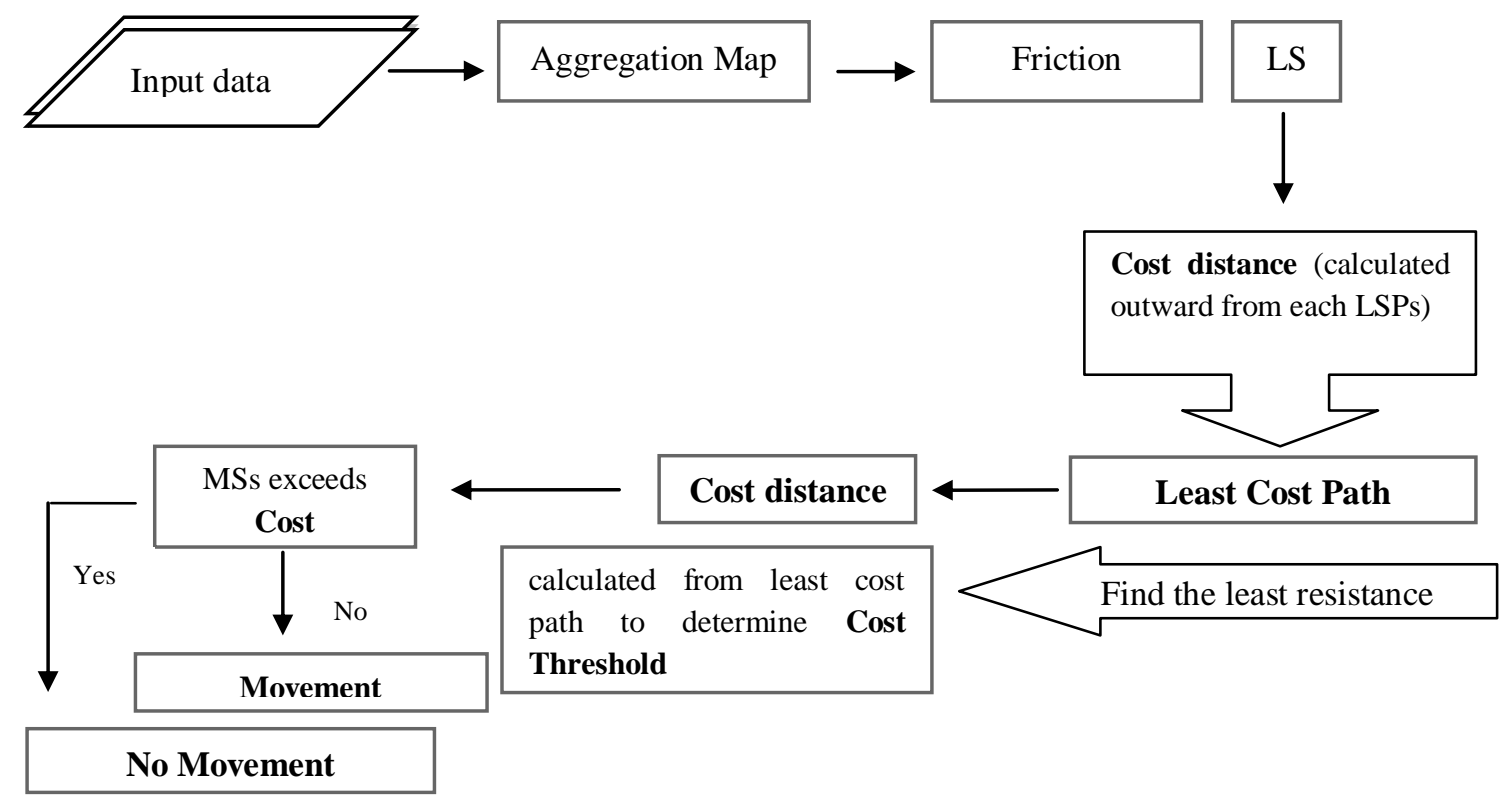

Figure 3. Flow chart for the procedure of least cost movement corridors, (LSP) local subpopulation and (MS) Movement suitability (Aggregtion map) 
We designed the width of movement corridors to be between 1 and $2.5 \mathrm{~km}$ to enable unobstructed movement of target species. Afterwards, length, area and perimeter of corridors were calculated for before and after conditions and changes were evaluated. Moreover, differences in habitat suitability of movement corridors were examined by detecting total suitability of each corridor and cost of moving in corridors were compared for before and after constructions.

\section{Results}

Our findings indicate that local subpopulations of target species and their movement corridors are negatively affected from dam constructions. The first prominent adverse effects of dams are that habitats of some local subpopulations are going to be flooded while some others are split into smaller discrete subpopulations (Fig. 4a, Fig. 5a and Fig. 6a). Almost half of the one local subpopulation of golden jackal (population-1) has already remained under reservoir of the Muratli Dam, and one of the local subpopulation of wild goat (population-3) will be flooded by Yusufeli Dam in the near future (2018) (Fig. 4d,e,f and Fig. 5d,e,f). Moreover, one golden jackal subpopulation (population-2) was divided into two small discrete subpopulations when Borçka Dam became operational in 2012 (Fig. 4d, $e$ and $f$ ) and one subpopulation of lynx (population-2) will be fragmented as well after Yusufeli Dam is completed (Fig. 6d,e,f). Several local subpopulations of target species become smaller after dam construction by either remaining under water or being fragmented with reservoirs.

A further finding is that some movement corridors of target species disappear after dam construction due to reservoirs acting as absolute barriers and preventing formation of movement corridors for target species. This is mostly observed for lynx, for which movement corridors between population 1 and 2, population 1 and 4, and population 3 and 4 could not be generated after completion of the dams. This means that lynx subpopulations remain isolated and thus, movements between subpopulations become impossible (Fig. 6). Wild goat sub-populations remain better connected than the lynx since formation of movement corridors was only blocked between populations 1 and 3 (Fig. 5b,e). In contrast, corridors for golden jackal are not much affected by dam constructions. The movement corridors formed are of similar configuration, although some now connect even smaller sub-populations formed after fragmentation of original suitable habitat (Fig. 4d, f).

Another observed effect of dams on movement corridors is related with the configuration of corridors. Reservoirs lead to changes in the physical parameters of some corridors such as area, length and perimeter (Table 2). Such changes are at moderate levels for golden jackal (only to $14.62 \%$ decline in corridor area). However, declines in this parameter reach serious levels for wild goat $(45.57 \%$ decline) and lynx (57.95\% decline). Movement corridors for the latter two species are either completely removed or some branches of corridors cannot be constituted following dam constructions - in some cases, a new, completely different corridor is generated (Fig. 5 and Fig. 6). As a result, roughly half of the movement corridors of wild goat and lynx are lost after all dam reservoirs are filled with water. Overall, the total costs of movement increase slightly for jackal, moderately for wild goat, and a great deal for lynx (Table 3). Similarly, a decline in habitat suitability of corridors is evident, with losses of relative suitability reaching $26.36 \%, 41.45 \%$ and $112.12 \%$ respectively for golden jackal, wild goat and lynx (Table 3). 

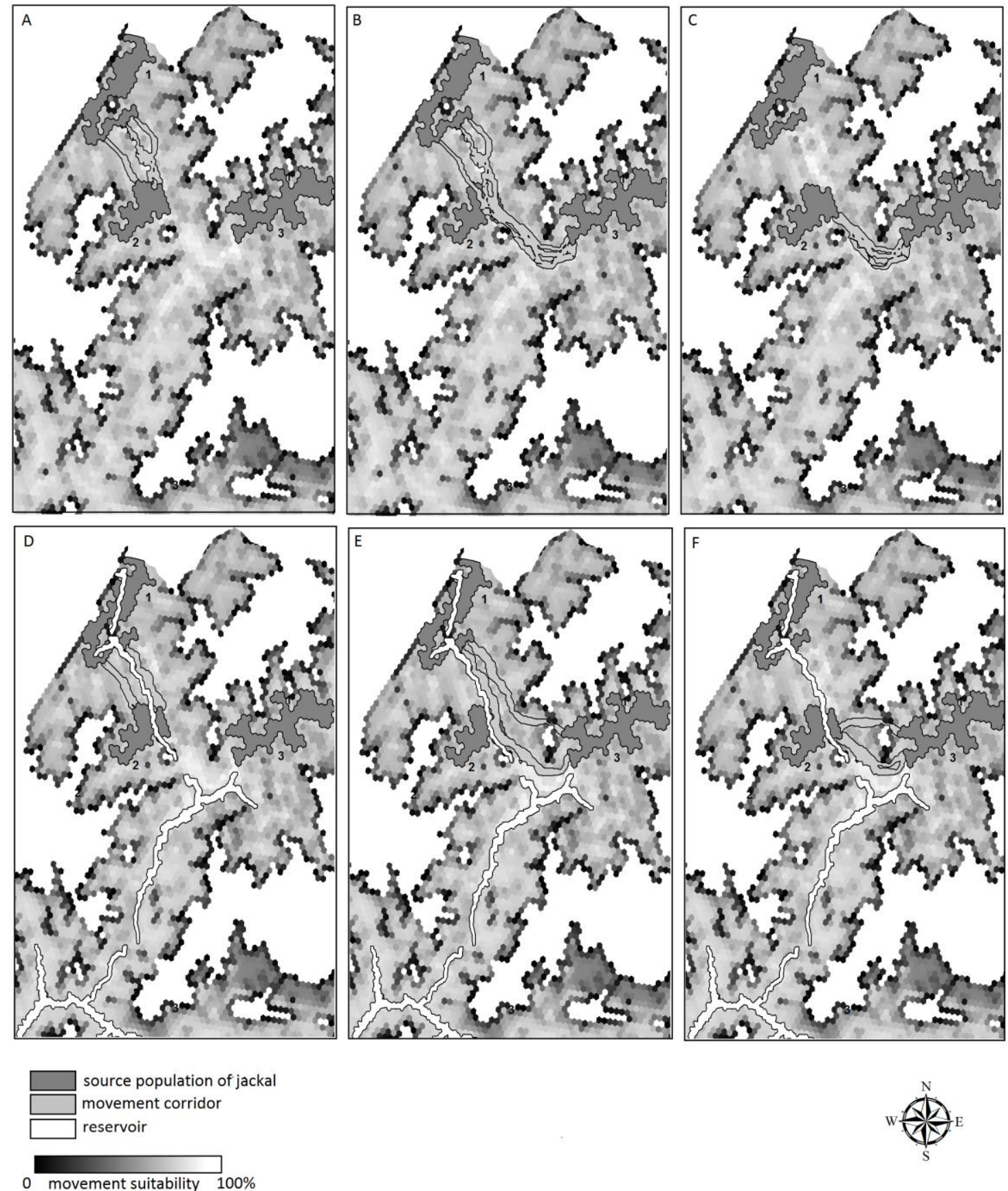

Figure 4. Movement corridors of golden jackal before (upper row) and after (lower row) dam construction, between populations 1-2 (left column), between populations 1-3 (middle column), and between populations 2-3 (right column) respectively

Dam constructions will not only change the route and structure of movement corridors, but also remove prime habitats of target species. An estimated 80.58\% (137 $\left.\mathrm{km}^{2}\right), 65.24 \%\left(111 \mathrm{~km}^{2}\right)$ and $28.80 \%\left(49 \mathrm{~km}^{2}\right)$ of the built or planned reservoir area is prime habitat of golden jackal, wild goat and lynx respectively, and will disappear after dam constructions. Moreover, the cost of movement (measured as a function of distance traveled and habitat suitability) increases up to $50 \%$ for some corridors after dam 
building (Table 3). This means that linkages between subpopulations are expected to become weaker compared to when dams were non-existent.
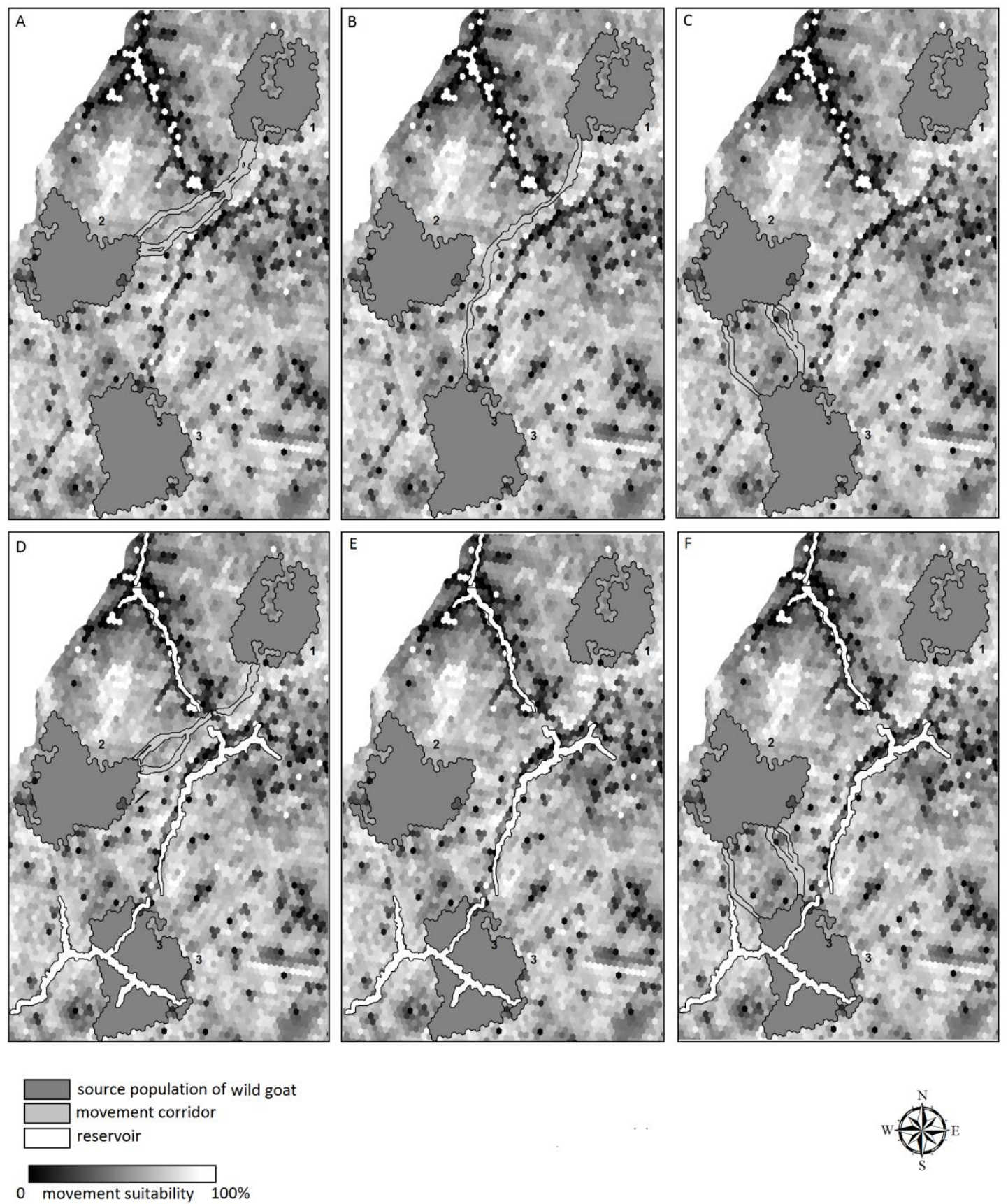

Figure 5. Movement corridors of wild goat before (upper row) and after (lower row) dam construction, between populations 1-2 (left column), 1-3 (middle column) and 2-3 (right column) respectively 

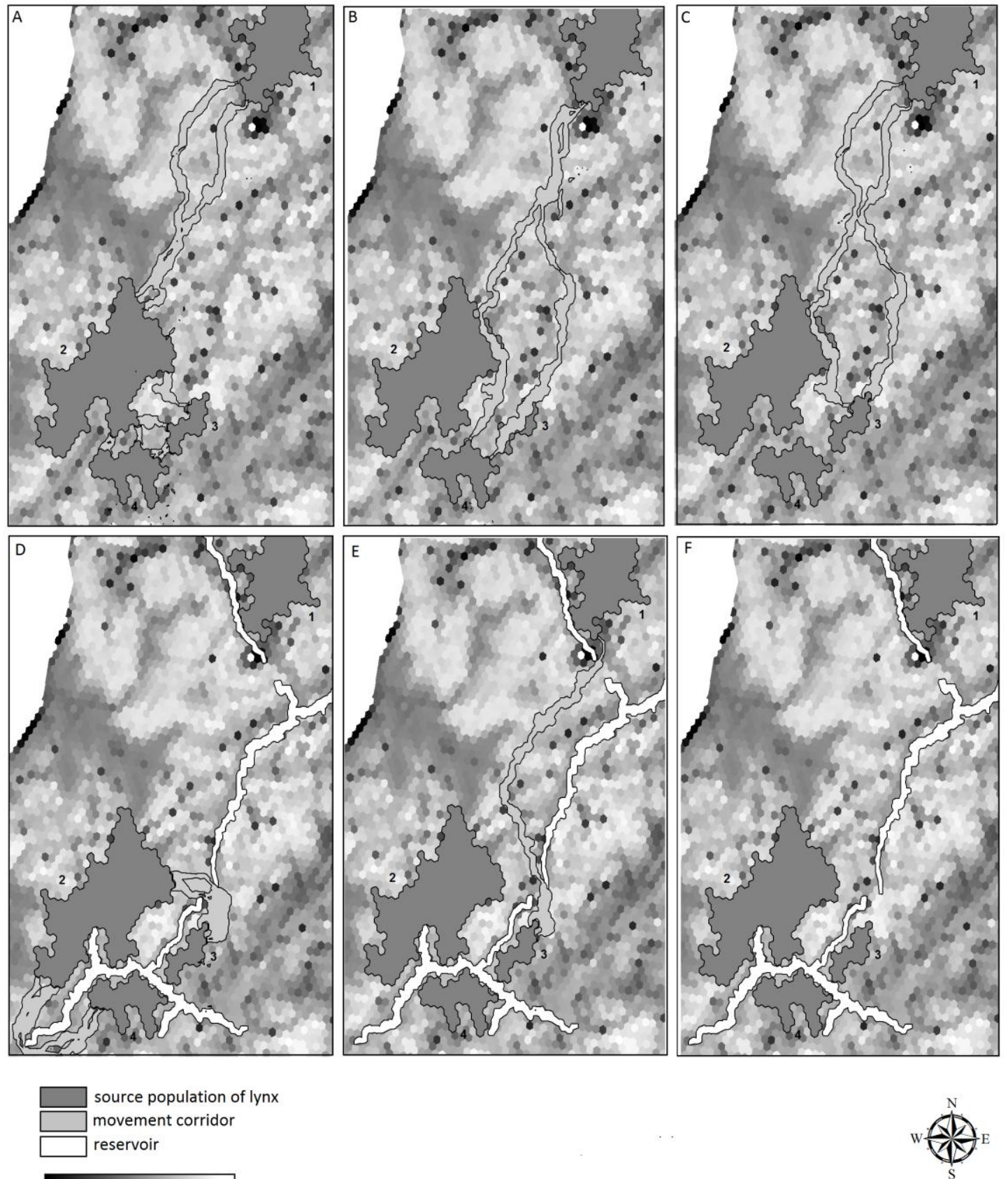

0 movement suitability $100 \%$

Figure 6. Movement corridors of lynx before (upper row) and after (lower row) dam construction, between populations 1-2, 2-3, 2-4 and 3-4 (left column), between populations 1-3 (middle column), and between populations 1-4 (right column), respectively 
Table 2. Total decrease in the physical structures of movement corridors according to the situations before and after dam constructions

\begin{tabular}{|c|c|c|c|c|}
\hline \multicolumn{2}{|c|}{ Corridor between } & $\begin{array}{c}\text { Area }\left(\mathrm{km}^{2}\right) \\
\text { Golden Jackal }\end{array}$ & Length $(\mathrm{km})$ & Perimeter $(\mathrm{km})$ \\
\hline Before & $\begin{array}{l}\text { LSP 1-2 (three branch) } \\
\text { LSP 1-3 (three branch) } \\
\text { LSP 2-3 (three branch) }\end{array}$ & $\begin{array}{c}\text { Golden Jackal } \\
34.18 \\
95.89 \\
43.78\end{array}$ & $\begin{array}{c}32.54 \\
104.55 \\
51.6\end{array}$ & $\begin{array}{l}108.15 \\
272.22 \\
120.26\end{array}$ \\
\hline $\begin{array}{c}\text { After } \\
\% \text { decrease }\end{array}$ & $\begin{array}{l}\text { LSP 1-2 (three branch) } \\
\text { LSP 1-3 (two branch) } \\
\text { LSP 2-3 (three branch) } \\
\text { total }\end{array}$ & $\begin{array}{c}30.86 \\
76.80 \\
40.78 \\
14.62\end{array}$ & $\begin{array}{c}29.90 \\
57.90 \\
99.67 \\
0.65\end{array}$ & $\begin{array}{c}76.40 \\
175.90 \\
42.04 \\
41.21\end{array}$ \\
\hline Before & $\begin{array}{l}\text { LSP 1-2 (three branch) } \\
\text { LSP 1-3 (one branch) } \\
\text { LSP 2-3 (three branch) }\end{array}$ & $\begin{array}{c}\text { Wild Goat } \\
62.82 \\
51.37 \\
37.79\end{array}$ & $\begin{array}{c}66.8 \\
131.33 \\
116.28\end{array}$ & $\begin{array}{c}164.92 \\
49.5 \\
39.7\end{array}$ \\
\hline After & $\begin{array}{l}\text { LSP 1-2 (three branch) } \\
\text { LSP 1-3 (no branch) } \\
\text { LSP 2-3 (three branch) } \\
\text { total }\end{array}$ & $\begin{array}{c}44.93 \\
0.00 \\
37.79 \\
45.57\end{array}$ & $\begin{array}{c}48.6 \\
0.00 \\
116.28 \\
47.56\end{array}$ & $\begin{array}{c}91.76 \\
0.00 \\
39.7 \\
48.27\end{array}$ \\
\hline Before & $\begin{array}{l}\text { LSP 1-2 (three branch) } \\
\text { LSP 1-3 (three branch) } \\
\text { LSP 1-4 (three branch) } \\
\text { LSP 2-3 (two branch) } \\
\text { LSP 2-4 (three branch) } \\
\text { LSP 3-4 (two branch) }\end{array}$ & $\begin{array}{c}\text { Lynx } \\
77.71 \\
118.14 \\
124.41 \\
14.13 \\
4.77 \\
3.28\end{array}$ & $\begin{array}{c}69.57 \\
94.9 \\
118.5 \\
9.6 \\
6.9 \\
6.7\end{array}$ & $\begin{array}{c}191.79 \\
310 \\
303.19 \\
49.75 \\
27.55 \\
27.52\end{array}$ \\
\hline$\%$ decrease & $\begin{array}{l}\text { LSP 1-2 (no branch) } \\
\text { LSP 1-3 (three branch) } \\
\text { LSP 1-4 (no branch) } \\
\text { LSP 2-3 (three branch) } \\
\text { LSP 2-4 (two branch) } \\
\text { LSP 3-4 (no branch) } \\
\text { total }\end{array}$ & $\begin{array}{c}0.00 \\
61.8 \\
0.00 \\
34.59 \\
47.61 \\
0.00 \\
57.95\end{array}$ & $\begin{array}{c}0.00 \\
48.5 \\
0.00 \\
73.18 \\
47.4 \\
0.00 \\
44.78\end{array}$ & $\begin{array}{c}0.00 \\
157.18 \\
0.00 \\
41.7 \\
116.15 \\
0.00 \\
63.37\end{array}$ \\
\hline
\end{tabular}

"LSP" is local sub-population 
Table 3. Comparisons of habitat suitability and total cost of movement in movement corridors for before and after dam constructions

\begin{tabular}{|c|c|c|c|c|}
\hline Corridor between & \multicolumn{2}{|c|}{ Habitat suitability } & \multicolumn{2}{|c|}{ Total cost in movement } \\
\hline Golden Jackal & Before & After & Before & After \\
\hline LSP $1-2$ & 7731.89 & 5824.51 & 339026.84 & 433973.537 \\
\hline LSP 1-3 & 22145.22 & 16045.43 & 3129723.03 & 3765873.71 \\
\hline LSP $2-3$ & 9544.19 & 7161.14 & 615990.69 & 764980.66 \\
\hline Total change & \multicolumn{2}{|c|}{$21.55 \%$ decrease } & \multicolumn{2}{|c|}{$26.36 \%$ increase } \\
\hline \multicolumn{5}{|l|}{ Wild Goat } \\
\hline LSP $1-2$ & 11688.39 & 9330.2 & 3649136 & 3763724.34 \\
\hline LSP 1-3 & 9087.03 & no corridors & 3641010.09 & no corridors \\
\hline LSP $2-3$ & 6838.45 & 6838.45 & 858730.7 & 858730.7 \\
\hline Total change & \multicolumn{2}{|c|}{$2.54 \%$ decrease } & \multirow{2}{*}{\multicolumn{2}{|c|}{$41.45 \%$ decrease }} \\
\hline \multicolumn{3}{|l|}{ Lynx } & & \\
\hline LSP $1-2$ & 18057.45 & no corridors & 2666289.87 & no corridors \\
\hline LSP 1-3 & 28010.14 & 14339.84 & 2199091.23 & 4046865.58 \\
\hline LSP 1-4 & 29646.78 & no corridors & 4811656.2 & no corridors \\
\hline LSP 2-3 & 3360.56 & 7945.88 & 318993.85 & 65737.79 \\
\hline LSP 2-4 & 3406.95 & 10565.57 & 13086.32 & 845485.34 \\
\hline LSP $3-4$ & 1959.54 & no corridors & 8887.96 & no corridors \\
\hline Total change & \multicolumn{2}{|c|}{$174 . .40 \%$ decrease } & \multicolumn{2}{|c|}{$112.12 \%$ increase } \\
\hline
\end{tabular}

\section{Discussion}

The efficacy of corridors in wildlife conservation has been a subject for discussion for a long time (Rosenberg et al., 1997; Niemela, 2001; Dixon et al., 2006). Several studies on mammal dispersal suggest that animal movement usually takes place within available suitable habitats (McLellan and Hovey, 2001; Poole et al., 2001; Maehr et al., 2002; Crooks and Sanjanyan, 2006; Cushman et al., 2013; Mateo-Sanchez et al., 2014). Therefore, degradation, loss or fragmentation of suitable habitats by man-made barriers such as highways, dams and other structures may seriously affect mobility of animals. In our study, models indicated that dams will lead to serious habitat fragmentation (Fig 4, 5 and 6 ), and thereby target species (and perhaps other ecologically related species) will be forced to live in restricted habitats and/or to migrate into new environments. Reductions in the quality of habitat within corridors and/or an increase in distances to travel will act to restrict mobility of target species and weaken linkages between separate patches. This implies that individuals would meet insufficient habitats encounter increased risks while moving between subpopulations (Fletcher et al., 2007). Furthermore, such isolated small populations tend to lose genetic variability and experience increased levels of inbreeding depression (Crnokrak and Roff, 1999).

Moreover, it is highly probable that local subpopulations will become smaller and isolated once the constructions are completed. This would increase the likelihood of rapid fluctuations in abundances and local extinctions in the face of environmental stochasticity. This is of particular concern for wild goat population-3, which largely overlaps with a wildlife reserve but will be divided into three fragments by the reservoir 
of Yusufeli Dam once it is built. In short, a combination of above mentioned effects may eventually drive target species populations to local extinctions.

Furthermore, our theoretical results indicate that dam constructions will remove prime habitat of some target species. In our case, golden jackals appear to be worst impacted through loss of habitat. However, the fact that jackals are opportunistic mammals that can tolerate human presence may help the species to survive in the future. Yet other species might suffer more from the loss of a considerable portion of their preferred habitat.

Dams on River Coruh were planned to be built sequentially with a maximum of $3 \mathrm{~km}$ gap between each. A route connecting two adjacent sub-populations through any of these gaps is on average about $19 \mathrm{~km}$. This is a relatively long distance for any of our target species. More importantly suitable structures for wildlife to use at the crossings do not currently exist at any of the gaps. This problem can be solved by establishing artificial structures at gaps between neighboring reservoirs. Such structures are generally in the form of overhead passes for large animals (Glista et al., 2009). They may need to be supported with fence blocks to protect animals from falling into reservoirs while trying to get across. Unfortunately, such solutions are rather costly, particularly when a number of them are required.

Large dams are known to have an effect on aquatic ecosystems through formation of artificial lakes and changes in hydrology of river systems. It is predicted that food webs and other ecological processes may be negatively affected by reservoirs (Kingsford, 2000). Relatively less known are impacts on the local microclimate following changes in evaporation, humidity and precipitation pattern (UNEP, 2000; Lagadinou, 2003). We demonstrate here that impacts on wildlife, particularly on large and medium mammals, also need to be taken into account whenever large-scale dam construction is planned. Extensive monitoring of populations likely to be impacted, and field research to better understand how animals adapt to their newly formed landscape are urgently needed to develop sound solutions against the irreversible ecological impact of dams on wildlife.

Acknowledgements. The habitat suitability models for jackal, lynx and wild goat were produced for the Turkish Lesser Caucasus Gap Analysis Project. This project was supported by the Turkish Foundation for Combating Soil Erosion, for Reforestation and the Protection of Natural Habitat (TEMA) and BakuTbilisi-Ceyhan (BTC) Pipeline Environmental Investment Programme. All analysis of the study was performed using Andes edition of Idrisi software and Arc-GIS 9.2.

\section{REFERENCES}

[1] Ambarl, H., Bilgin, C. C. (2008): Human-Brown Bear Conflicts in Artvin, Northeastern Turkey: Encounters, Damage, and Attitudes. - Ursus 19(2):146-153.

[2] Ambarlı, H., Mengüllüoğlu, D., Bilgin, C. C. (2010): First camera trap pictures of Eurasian Lynx from Turkey. - Cat News 52, pp 32.

[3] Ambarl1, H., Bilgin, C. C. (2012): First record of a melanistic golden jackal (Canis aureus) from Turkey. - Mammalia 77(2):219-222.

[4] Anderson, A. B., Jenkins, C. N. (2006): Applying nature's design: corridors as a strategy for biodiversity conservation. - Columbia University Press, New York.

[5] Beier, P. (1993): Determining minimum habitat areas and habitat corridors for cougars. Conservation Biology 7:94-108.

[6] Beier, P., Noss, R. F. (1998): Do habitat corridors provide connectivity? - Conservation Biology 12:1241-1252. 
[7] Beier, P., Penrod, K. L., Spencer, W. D., Cabanero, C. (2006): South cost missing linkages: restoring connectivity to wildlands in the largest metropolitan area in the United States. - In: Crooks KR, Sanjayan M, eds. Connectivity conservation, Cambridge University Press, Newyork, pp. 555-586.

[8] Beier, P., Majka, D. R., Spencer, W. (2008): Forks in the road: choices in procedures for designing wildlife linkages. - Conservation Biology 22:836-851.

[9] Beier, P., Majka, D. R., Newell, S. L. (2009): Uncertainty analysis of least-cost modeling for designing wildlife linkages. - Ecological Applications 19:2067-2077.

[10] Beier, P., Spencer, W., Baldwin, R. F., Mcrae, B. H. (2011) Towards best practices for developing regional connectivity maps. - Conservation Biology 25:879-892.

[11] Bentley, J. M., Catteral, C. P. (1997): The use of brushland corridors and linear remnants by birds in southeastern Queensland Australia. - Conservation Biology 68:155-165.

[12] Bilgin, C. C., Zeydanlı, U., Bal, M. (2006): Lesser Caucasus Gap Analysis Project Final Report (unpublished report). Middle East Technical University, Turkey.

[13] Blanco, J. C., Cortes, Y., Virgos, E. (2005): Wolf response to two kinds of barriers in an agricultural habitat in Spain. - Canadian Journal of Zoology 83(2):312-323.

[14] Briers, R. A. (2002): Incorporating connectivity into reserve selection procedures. Biological Conservation 103:77-83.

[15] Chetkiewicz, C. L. B., Boyce, M. S. (2009): Use of resource selection functions to identify conservation corridors. - Journal of Applied Ecology 46:1036-1047.

[16] Clevenger, A. P., Wierzchowski, J., Chruszcz, B., Gunson, K. (2002): GIS-generated, expert-based model for identifying wildlife habitat linkages and planning mitigation passages. - Conservation Biology 16:503-514.

[17] Crnokrak, P., Roff, D. A. (1999): Inbreeding depression in the wild. - Heredity 83:260270.

[18] Crooks, K. R., Sanjayan, M. (2006): Connectivity conservation. - Cambridge University Press, Newyork.

[19] Cushman, S. A., McRae, B., Adriansen, F., Beier, P., Shirley, M., Zeller, K. (2001): Biological corridors and connectivity. - In Conservation in theory and practice: 284-404, Mcdonald, D. (Ed.). Oxford: Blackwell.

[20] Dixon, J. D., Oli, M. K., Wooten, M. C., Eason, T. H., McCown, J. W., Paetkau, D. (2006): Effectiveness of a regional corridor in connecting two Florida black bear populations. - Conservation Biology 20:155-162.

[21] Eminağaoğlu, Ö., Anşin, R. (2003): The Flora of Hatila Valley National Park and its Close Environs (Artvin). - Turkish Journal of Botany 27:1-27.

[22] Fagan, W. F., Calabrese, J. M. (2006): Quantifying connectivity: balancing metric performance with data requirements. - In: Crooks KR, Sanjayan M, eds. Connectivity conservation, Cambridge University Press, Newyork, pp. 297-317.

[23] Fahrig, L., Merriam, G. (1994): Conservation of fragmented populations. Conservation Biology 8:50-59.

[24] Fletcher, R. J., Ries, J. R. L., Battin, J., Chalfoun, A. D. (2007): The role of habitat area and edge in fragmented landscapes: definitively distinct or inevitably intertwined? Canadian Journal Zoology 85:1017-1030.

[25] Glista, D. J., DeVault, T. L., DeWoody, J. A. (2009): A review of mitigation measures for reducing wildlife mortality on roadways. - Landscape Urban Planning 91:1-7.

[26] Gokturk, T., Bucak, F., Artvinli, T. (2011): Mammalian Fauna of Artvin. - African Journal Agricultural Research 6(6):1418-1425.

[27] Gundogdu, E., Ogurlu, I. (2009): The Distribution of Wild Goat Capra aegagrus Erxleben 1877 and Population Characteristics in Isparta, Turkey. - Journal of Animal and Veterinary Advances 8(11):2318-2324.

[28] Gundogdu, E. (2011): Population Size, Structure and Behaviours of Wild Goat in Cehennemdere Wildlife Improvement Area. - Asian Journal of Animal Veterinary Advances 6:555-563. 
[29] Haddad, N. M., Baum, K. A. (1999): An experimental test of corridor effects on butterfly densities. - Ecological Applications 9:623-633.

[30] Hale, M. L., Lurz, P. W. W., Shirley, M. D. F., Rushton, S., Fuller, R. M., Wollf, K. (2000): Impact of landscape management on the genetic structure of red squirrel populations. - Science 293:2246-2248.

[31] Harrison, S., Voller, J. (1998): Connectivity, In: Harrison S, Voller J, eds. Conservation biology principles for forested landscapes. - University of British Columbia Press, Vancouver, pp. 76-97.

[32] Jhala, Y. V., Moehlman, P. D. (2004): 6.2. Golden Jackal Canis aureus Linnaeus, 1758. In: Sillero Z, Hoffmnn CM, Macdonald DW (eds): Canids: Foxes, Wolves, Jackals and Dogs. Status, Survey and Conservation Action Plan. - IUCN/SSC Canid Specialist Group, Gland, Switzerland and Cambridge, UK, pp. 156-161.

[33] Jogman, R. (2004). The context and concept of ecological networks. In: Jongman R, Pungetti G, eds. Ecological networks and Greenways Concept, Design and Implementation. - Cambridge University Press, pp. 7-33.

[34] Kingsford, R. T. (2000): Ecological impacts of dams, water diversions and river management on floodplain wetlands in Australia. - Austral Ecolgy 25:109-127.

[35] Kintsch, J., Cramer, P. C. (2011): Permeability of Existing Structures for Terrestrial Wildlife: A Passage Assessment System. - Report to the Washington State Department of Transportation, Research Report No. WA-RD 777.1.

[36] Kovacs, J. M., Malczewski, J., Verdugo, F. F. (2004): Examining local ecological knowledge of hurricane impacts in mangrove forest using analytical hierarchy process (AHP) approach. - Journal of Coastal Research 20:792-800.

[37] Kusak, J., Huber, D., Gomercic, T., Schwaderer, G., Guzvica, G. (2009): The permeability of highway in Gorski Kotar (Croatia) for large mammals. - European Journal of Wildlife Research 55:7-21.

[38] Lapini, L., Conte, D., Zupan, M., Kozlan, L. (2011): Italian Jackals 1984-2011: An updated review (Canis aureus: Carnivore, Canidae). - Boll Mus St Nat Venezia, 62:219232.

[39] LaPoint, S., Gallery, P., Wikelski, M., Kays, R. (2013): Animal behavior, cost based corridor models and real corridors. - Landscape Ecology 28(8):1615-1630.

[40] Lagadinou, E. (2003): Assessment of the impact of artificial reservoirs to the microclimate. - Postgraduate Thesis, Department of Water Resources, Hydraulic and Maritime Engineering, National Technical University of Athens, Athens.

[41] Larkin, J. L., Maehr, D. S., Hoctor, T. S., Orlando, M. A., Whitney, K. (2004): Landscape linkages and conservation planning for black bear in the west central Florida. Animal Conservation 7:23-34.

[42] Laure, M. A., Nielsen, C. K. (2008): Modeling potential dispersal corridors for cougars in Midwestern North America using least- cost path methods. - Ecological Modeling 212: 372-381.

[43] MacClintock, L., Whitcomb, R. F., Whitcomb, B. L. (1977). Evidence for the value of corridors and minimization of isolation in preservation of biotic diversity. - American Birds 31:6-12.

[44] Macdonald, M. A. (2003): The role of corridors in biodiversity conservation in production forest landscapes: a literature review. - Tasforests 14:41-52.

[45] Machtans, C. S., Villard, M. A., Hannon, S. J. (1996): Use of riparian buffer strips as movement corridors by forest birds. - Conservation Biology 10:1366-1379.

[46] Maehr, D. S., Land, E. D., Shindle, D. B., Bass, O. L., Hoctor, T. S. (2002): Florida panther dispersal and conservation. - Biological Conservation 106:187-197.

[47] Manel, S., Schwartz, M.K., Luikart, G., Taberlet, P. (2003): Landscape genetics: combining landscape ecology and population genetics. - Trends in Ecology and Evolution 18:189-197. 
[48] Mateo-Sanchez, M. C., Cushman, S. A., Saura, S. (2014): Connecting endangered brown bear subpopulations in the Cantabrian Range (north-western Spain). - Animal Conservation 17:430-440.

[49] McLellan, B. N., Hovey, F. W. (2001): Natal dispersal of grizzly bears. Canadian Journal of Zoology 79:838-844.

[50] Merriam, G., Lenoue, A. (1990): Corridor use by small mammals: field measurements for three experimental types of Peromyscus leucopus. - Landscape Ecology 4:123-131.

[51] Mills, L. S., Smouse, P. E. (1994): Demographic consequences of inbreeding in remnant populations. - American Naturalist 144:412-431.

[52] Morrison, S. A., Boyce, W. M. (2008): Conserving connectivity: some lessons from mountain lions in southern California. - Conservation Biology 23:275-285.

[53] Myers, N., Mittermeier, R. A., Mittermeier, C. G., Da Fonseca, G. A. B., Kent, J. (2000): Biodiversity hotspots for conservation priorities. - Nature 403:853-858.

[54] Niemela, J. (2001): The utility of movement corridors in forested landscapes. Scandinavian Journal of Forest Research 3:70-78.

[55] Noss, R. F., Quigley, H. B., Hornocker, M. G., Merrill, T., Paquet, P. (1996): Conservation biology and carnivore conservation. - Conserv Biol 10:949-963.

[56] Nowel, K., Jackson, P. (1996): IUCN/SSC Cat Specialist Group. Wild cats: status survey and conservation action plan. - Gland (Switzerland), IUCN.

[57] Parks, S. A., Mckelvey, K. S., Schwartz, M. K. (2013): Effects of weighting schemes on the identification of wildlife corridors generated with least-cost methods. - Conservation Biology 27(1):145-154.

[58] Poole, K. G., Mowat, G., Fear, D. A. (2001): DNA-based population estimation for grizzly bears Ursus arctos in northeastern British Columbia, Canada. - Wildlife Biology 7: 105-115.

[59] Poor, E. E., Loucks, C., Jakes, A., Urban, D. L. (2012): Comparing habitat suitability and connectivity modeling methods for conserving pronghorn migrations. - PLoS One 7:e49390.

[60] Proctor, M. F., McLellans, B. N., Strobeck, C., Barclay, R. M. R. (2004): Gender-specific dispersal distances of grizzly bears estimated by genetic analysis. - Canadian Journal of Zoology 82:1108-1118.

[61] Riley, S. P. D., Pollinger, J. P., Sauvajot, R. M., York, E. C., Bromley, C., Fuller, T. K., Wayne, R. K. (2006): A southern California freeway is a physical and social barrier to gene flow in carnivores. - Molecular Ecology 15:1733-1741.

[62] Rosenberg, D. K., Noon, B. R., Meslow, C. (1997): Biological Corridors: Form, Function, and Efficacy. - Bioscience 47(10):677-687.

[63] Samlius, G., Andren, H., Liberg, O., Linnell, J. D. C., Odden, J., Ahlqvist, P., Segerström, P., Sköld, K. (2011): Spatial and temporal variation in natal dispersal by Eurasian lynx in Scandinavia. - Journal of Zoology 286(2):120-130.

[64] Saura, S., Bodin, Ö., Fortin, M. J. (2014): Stepping stones are crucial for species long distance dispersal and range expansion through habitat networks. - Journal of Applied Ecology 51:171-182.

[65] Sawyer, S. C., Epps, C. W., Brashares, J. S. (2011): Placing linkages among fragmented habitats: do least-cost models reflect how animals use landscapes? - Journal of Applied Ecology 48:668-678.

[66] Schmidt, K. (1998): Maternal behavior and juvenile dispersal in the Eurasian Lynx. Acta Theriologica 43(4):391-408.

[67] Sekercioglu, C. (2012): Turkey's First Wildlife Corridor Links Bear, Wolf and Lynx Populations to the Caucasus Forest. - http://voices.nationalgeographic.com /2012/02/13/turkeys-first-wildlife-corridor-links-bear-wolf-and-lynx-populations-to-thecaucasus-forests/.

[68] Shackleton, D. M. (1997): Wild Sheep and Goats and their Relatives: Status Survey and Conservation Action Plan for Caprinae. - IUCN, Gland, Switzerland. 
[69] Shkedy, Y., Saltz, D. (2000): Characterizing core and corridor use by Nubian Ibex in the Negev desert, Israel. - Conservation Biology 14:200-206.

[70] Store, R., Kangas, J. (2001): Integrating spatial multi-criteria evaluation and expert knowledge for GIS-based habitat suitability modeling. - Landscape and Urban Planning 55:79-93.

[71] Sucu, S., Dinç, T. (2008): Çoruh Basin Projects. - Downloaded from http://www.imo.org.tr/resimler/ekutuphane/pdf/10912.pdf on 8 May 2015 (in Turkish).

[72] Turan, N. (1984): Game and Wild Animals-Mammals of Turkey. - Ministry of Forest Publications, Ankara, 87 pp. (in Turkish).

[73] United Nations Environment Programme (UNDP), (2000): CLIMATE CHANGE AND DAMS: An Analysis of the linkages between the UNFCCC Legal Regime and Dams. - In cooperation with The World Commission on Dams.

[74] Verbeylen, G., De Bruyn, L., Adriaensen, F., Matthysen, E. (2003): Does matrix resistance influence red squirrel (Sciurus vulgaris L. 1758) distribution in an urban landscape? - Landscape Ecology 18:791-805.

[75] Washington Habitat Connectivity Work Group (WHCWG), (2010): Connected landscapes project. - WHCWG Available from http://www.waconnected.org/.

[76] Way, J. G. (2009): Observations of Coywolves, Canis latrans $\times$ lycaon, Crossing Bridges and Using Human Structures on Cape Cod, Massachusetts. - Canadian Field Naturalist 123(3):206-209.

[77] Zeller, K. A., McGarigal, K., Whiteley, A.R. (2012): Estimating landscape resistance to movement: a review. - Landscape Ecology 27:777-797. 